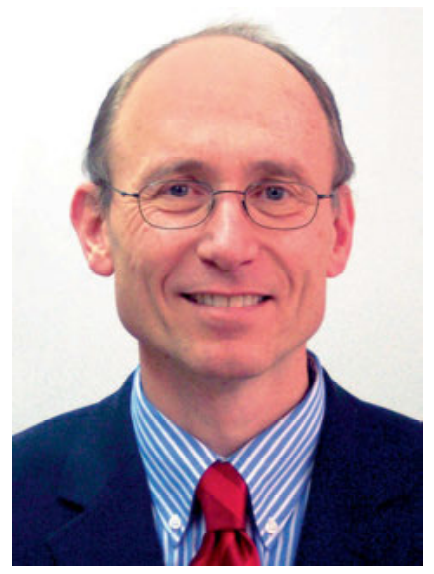

\title{
Grußwort des seit November 2008 amtierenden Rektors
}

Als neuer Rektor der Heinrich-Heine-Universität Düsseldorf nutze ich die Gelegenheit, alle Kolleginnen und Kollegen, Mitarbeiterinnen und Mitarbeiter, die Studierenden sowie alle weiteren interessierten Leserinnen und Leser dieses Jahrbuchs unserer Universität herzlich zu begrüßen. Das Jahrbuch zeigt die beeindruckende Vielfalt unseres akademischen Schaffens und die daraus erwachsenden Verbindungen mit Gesellschaft, Wirtschaft und Kultur. Das eigentliche Vorwort gebührt meinem Amtsvorgänger, Herrn Univ.-Prof. Dr. Dr. Alfons Labisch. Herrn Univ.-Prof. em. Dr. Hans Süssmuth sei für die aufwändige redaktionelle Arbeit gedankt, die dem Jahrbuch Inhalt und Form gegeben hat.

Düsseldorf, im November 2008

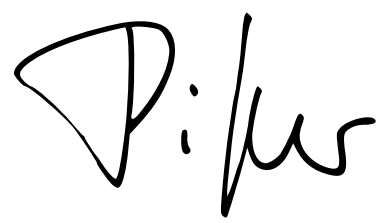

Univ.-Prof. Dr. Dr. H. Michael Piper 
